continue to visit children on a regular basis and to concentrate on families with problems.

We do not report this agreement in Northumberland because we think that it should be the blueprint for Britain or that we have discovered the ultimate truth about surveillance. The omission of some screening tests means not that they should not be done but rather that there was insufficient agreement about the test in Northumberland for it to form part of the scheme for evaluation. We do not know whether primary health care teams in Northumberland will do what they have agreed to or, even if they do, whether it will help children. We can, however, start to answer these questions because for the first time there is agreement between health visitors, family doctors, and clinical medical officers about what they should offer all children and what measures should be used to evaluate the effect of this.

We emphasise that the discussions with those working in primary care were stimulating and educational. Great interest was shown in surveillance as a concept and in its detail. It took the equivalent of only one month's work to obtain the agreement of all the primary health care teams in the district, and the agreements were introduced in January this year.

We thank all the family doctors, health visitors, clinical medical officers, and nursing officers in Northumberland; Dr F S Rogers (specialist in community medicine); Miss G Charlton (director of nursing, preventive child health); the Northumberland Local Medical Committee; and Mrs A Robinson for preparing the manuscript.

\section{References}

1 Committee on Child Health Services. Fit for the Future. London: HMSO, 1976. (Court report.) (Cmnd 6684.)

2 Royal College of General Practitioners. Healthier children: thinking prevention. London: Royal College of General Practitioners, 1982.

3 Health Visitors Association. The health visitor's role in child health surveillance. London: Health Visitors Association, 1985

4 General Medical Services Committee of the British Medical Association and Royal College of General Practitioners. Handbook of preventive care of preschoool children. London: BMA and Royal College of General Practitioners, 1984

(Accepted 13 May 1986)

\title{
Letter from . . . the Himalayas
}

\section{The central dilemma: destroy or develop}

\author{
T E LANKESTER
}

The high caste village of Badra is spectacularly perched on a midvalley saddle with commanding views of more than 20 settlements north and south. At the invitation of local leaders, a village meeting was in progress. The object of the evening was to draw a crowd through showing a film and to explain our health programme to as many as possible. The key question was this: how would the local deity, whose temple juxtaposed the meeting site, react to the infringement of her proprietary rites? We need not have worried. After a couching ceremony accompanied by bells and smells she was temporarily forgotten as the village gathered with unconcealed excitement. The silhouette of the projector against the moon draped semicircle of hills was magically surreal. The evening went well. As the last stragglers left the arena, having soundly participated in the evening's discussions, we realised that the first seeds of understanding about community health had gently been sown.

\section{Setting up a health programme}

Towards the end of 1984 I was asked jointly by local leaders and by an Indian health association to set up a health programme in the mid-Himalayas. Seven years as a suburban general practitioner and three years' exposure to Himalayan health problems failed to warn me how difficult this would be.

The hills and valleys of the Indian Himalayas are the home of many million hardy farmers, scattered in more than 50000 villages. Although generally not as remote as their Nepalese counterparts, such villages are often miles from the nearest road and cut off for weeks by snow in the winter or landslides in the monsoon. The

North India

T E LANKESTER, MRCGP, physician in community health
Indian government has an ambitious and commendable plan for building roads up many of the inhabited side valleys of these mountains. Already, north of the hill station where we live, villages which had been cut off for centuries now have access to the outside world with all the development and dangers which this implies.

Some of the most striking features of these mountain people are the simple pastoral logic and intelligent fatalism, which enable them so effectively to celebrate life's joys and to cope with its hardships. The resilience of family structure acts as a powerful insurance against the traumas of old age and bereavement. Indeed, in terms of social cohesion and its chief derivative, mental well being, these mountain farmers have much to teach our so called urban élites with their fragmented lifestyles.

Into such quiet and integrated communities the development worker arrives, his brain bulging with notions and his forms hungry to record the statistics of village backwardness. How much value would accrue to him and how much sadness would be avoided if someone were to explain that the timeless wisdom of rural centuries would enrich his life in measure exceeding that of the improvements he would share with his hearers.

\section{Dangers of development}

With each village community reflecting a delicate and finely tuned human ecology should any changes be introduced at all? In the equation of change might not the dangers of introducing hidden seeds of self destruction in the development package outweigh the benefits of correcting malnutrition, treating tuberculosis, and encouraging temperance?

Even the presence of a national outsider in a village community introduces a hidden suggestion that his unfamiliar clothes and lifestyle are intrinsically better than their village counterparts. The sadly mistaken notion that city ways are superior to village ways may 
be the enduring side effect of a visit, the prime purpose of which has long been forgotten. Moreover, health workers may forget that even the simplest corrective action sets off a chain reaction. An illness that before would have been left to run its course may now be referred for expensive surgery. Even with subsidy debts may be incurred. To the unfamiliar and cruel dilemma of choice is added the fear of exploitation, the guilt of veering from traditional practices, and a bondage to untrustworthy money lenders. We can already recognise the seeds of "dis-ease," which are possibly more sinister than those of the disease which they have supplanted.

Take again the well rehearsed but daily more destructive increase in the numbers of people. More interventions in cases of childhood measles and malnutrition mean more mouths to feed; if the gods are unfavourable there may be more girls in the family and more dowries to find; this can result in more debts to pay and more dependencies to face. The summation of the derived effects of scalpels and Septrin can unleash changes undreamed of by innocent health planners.

But the process does not end even here. Today there is great pressure on health planners to diversify into other forms of development. Ill health is a symptom, not a cause, of sick individuals and sick communities, and radical changes in other development areas are therefore essential. Soon a health professional is working alongside colleagues with expertise in agriculture, forestry, and rural engineering. Here both the potential rewards and potential dangers rise exponentially. The risk-reward index parallels the radicalness of the input. As one moves from pills to clean water, up through reafforestation and better crop varieties, to land reform, social justice, and the rights of the poor, the dynamics of village life can be altered beyond recognition. The implications of these changes are often masked by the comparative slowness of the process and by the acuity of the development worker, whose vested interests in the value of his contribution can blind him to its harmful side effects.

\section{First village clinic}

It is two months later. Our first village clinic near Badra is more than halfway through and soon we will be heading homewards on a three hour jeep ride. Patients have been thronging the clinic entrance, those clutching amoeba sodden intestines mingling with dehydrated, malnourished children and others crying with toothache. There have been the inevitable few loaded with sheaves of radiographs and bundles of laboratory reports from distant urban clinics, the Himalayan equivalent of the general practitioner's fat folder, signifying incurable disease, refractory neurosis, and unnecessary financial loss. Last, and perhaps least, have been the small band of those who are not sick at all-relatives of the landlord, women eager for a day away from their husbands and homes, and the innocently curious.

The very presence of a health clinic here in the hills symbolises the inevitability of the process of change. Development is in the wind and the wind blows where it wills. Whether we like it or not in five years' time communities world wide will be different from the way they are now. The delayed migration of certain Saharan tribes so as to complete their viewing of the last episode of Dallas underlines the possible consequences, if not the justification, of this galloping process.

\section{Thinking ahead}

Change dictates its own mandate. We are left with no alternative but to move ahead, trying at the same time to steer the development coach towards processes that are affirmative and not destructive of village life. We must support and encourage traditions and attitudes which are sociologically sound and guide the introduction of inputs which can enrich village life. Above all, we must avoid spreading the most deadly form of scabies in the developing world-an itch for the lights and glamour of the nearest city and a naive belief in streets lined with Whittingtonian gold.

We are nearly home. We have passed the present markers of a dozen old landslides, skin tags representing the piles of previous years. In the surging river below we have eyed the jeep sized boulders, which two years before spared our lives by inches as they hurtled from their million year old home in the cliffs above. Our team never doubts we should go back for more. Health for All carries with it a self authenticating vision and challenge which inspires a growing number of enthusiasts in countries such as this.
What is the mechanism of vomiting in upper gastrointestinal bleeding and why does it not occur after eating "black pudding?"

The questioner infers that blood has emetic properties. This has not been demonstrated. It would be surprising when one remembers that some cattle herding tribes in Africa drink the blood of their cattle as a major part of their diet. When haematemesis occurs and the blood is red, this is usually a sign of a large haemorrhage. The vomiting is probably due simply to gastric distension by the blood plus perhaps the general effects of hypotension and shock which would include gastric stasis. Many substantial gastric and duodenal haemorrhages do not lead to haematemesis but only to melaena. There remains the problem of so called coffee grounds vomitus. Here the size of the haemorrhage is often trivial. The vomiting is probably attributable to the cause of the bleeding such as acute gastric erosions or an alcoholic binge. A further possible factor is the rapid rise in blood urea that may occur when a large amount of blood protein is digested and absorbed and renal function is impaired due to hypovolaemia.- $\mathrm{K}$ W HEATON, reader in medicine, Bristol.

Low fat spreads seem a sensible part of a prudent diet since they reduce total fat intake. Can they be recommended in view of the type of fat used in their production? Do they contain a high proportion of saturated fats?

The primary value of the low fat spreads must be seen as their contribution to the reduction of overall fat intake ${ }^{1}$ and as substitutes for butter and margarine. In view of the advice to increase the consumption of complex carbohydrates there is merit in having low fat spreads that can accompany increased bread consumption. The spreads themselves are prepared using mixtures of fats, including vegetable oils, and have polyunsaturated: saturated ratios that are higher than butter and many margarines, ${ }^{2}$ although clearly not as high as the polyunsaturated margarines. The low fat spreads must therefore be seen as useful aids to dietary change.-D A T SOUTHGATE, head nutrition and food quality division, Food Research Institute, Norwich.

1 Department of Health and Social Security. Report on diet and cardiovascular disease. London: HMSO, 1984.

2 Paul AA, Southgate DAT. McCance and Widdowson's the composition of food. London: HMSO, 1978.

A 5 month old baby has Down's syndrome, congenital heart disease (cyanotic in the first few weeks), and cataract in one eye. It has been suggested that the cataract be removed, but the parents, both doctors, question this. They reason that the sight is unlikely to be improved if the aphakia is not corrected but spectacles are impractical, contact lenses even more so, and they have been told that a lens implant is inadvisable in a child younger than 6 years. Heart surgery will be needed later and they are clearly anxious to avoid unnecessary operations. What advice should be given?

At the age of 5 months his parents are quite correct in thinking that the sight is unlikely to be improved and what is more, however, even if the aphakia is corrected, whether by spectacles, intraocular lens, or contact lens, it is highly unlikely that any appreciable improvement in the long term vision will be achieved and any of these procedures carry with them considerable if not very substantial risks. In addition, the heart disease makes any surgical risks greater and I am sure that it would be better to do nothing at this stage but to keep under the care of an ophthalmologist who may agree to remove the cataract for cosmetic reasons. Although there have been some encouraging reports of good vision after very early surgery (before six weeks) in cases of unilateral cataract, these have not yet been confirmed.-DAVID TAYLOR, consultant ophthalmologist, London. 